\title{
KARYA SASTRA YANG TUMBUH DAN BERKEMBANG DALAM MASYARAKATTUTUR BAHASA BALI DI LOMBOK: SUATU KAJIAN BANDINGAN GEOGRAFIS
}

\section{(LITERATURES EMERGING AND DEVELOPING AMONG BALI SPEAKER COMMUNITY IN LOMBOK: A GEOGRAPHICAL COMPARATIVE SYUDY)}

\author{
Nining Nur Alaini \\ Kantor Bahasa Provinsi Nusa Tenggara Barat \\ Jalan dr. Sujono, Kelurahan Jempong Baru, Kecamatan Sekarbela, Kota Mataram \\ Pos-el: niningkirono@yahoo.com
}

Diterima: 13 November 2013; Direvisi: 6 Desember 2013; Disetujui: 7 Desember 2013

\begin{abstract}
People occupingthe areas of Nusa Tenggara Province are heterogeneous. Lombok island is a home for four main tribes and other minor migrant tribes. The four tribes are Sasak, Samawa, and Bali. The existence of the tribes is characterized by different identities. One of the identities is language and literature. It is highly likely that the area where a language exists will also have a literature. The variety of languages used in each area will possibly emerge specific literatures. As for the example, the Balinese living in Lombokislandenrich the treasure of Lombok literatures by bringing with them their own literature to Lombok. The geographical and social differences demand migrant community to adapt to the condition. Over a particular period, we will find some social and cultural differences as a result of adaptation to the new environment. The result of the adaptation will also be found in literatures. The variation of society, culture, and geography will birth variation of literatures. This research is aimed at finding a description on Balinese literatures emerging and developing in Sasak community.
\end{abstract}

Keywords: comparative study, literatures, variation

\begin{abstract}
Abstrak
Masyarakat yang mendiami wilayah-wilayah di Provinsi Nusa Tenggara Barat sangat majemuk. Pulau Lombok didiami oleh empat suku bangsa yang besar, di samping berbagai kelompok suku bangsa pendatang baru. Keempat suku tersebut adalah suku bangsa Sasak, Bima, Sumbawa dan suku bangsa Bali. Keberadaan masing-masing komunitas ditandai oleh identitas yang berbeda, yang salah satunya berwujud bahasa dan sastra. Dapat dikatakan bahwa setiap daerah yang mempunyai bahasa daerah sangat mungkin mempunyai sastra daerah. Adanya variasi-variasi bahasa yang digunakan di masingmasing wilayah sangat memungkinkan hidupnya karya-karya sastra yang juga khas di wilayah bahasa tersebut. Demikian juga dengan komunitas Bali yang menetap di Pulau Lombok. Keberadaan suku Bali di Lombok memperkaya khazanah kesastraan Lombok dengan dibawanya sastra Bali ke Lombok oleh pendatang-pendatang dari Bali tersebut. Perbedaaan sosial budaya dan geografis, menuntut masyarakat pendatang untuk menyesuaikan diri dengan kondisi wilayah baru yang ditempatinya. Dalam beberapa jangka waktu, kita akan menemukan beberapa perbedaan sebagai hasil adaptasi sosial budaya dan lingkungan baru. Hasil adaptasi yang disebut sebagai variasi ini, biasanya juga terjadi dalam karya sastranya. Adanya variasi sosial budaya dan geografis akan diikuti pula dengan munculnya variasi sastra. Dengan melakukan kajian bandingan geografis diharapkan dapat diperoleh gambaran tentang wujud kontak sastra Bali selama masa perjalanannya yang tumbuh dan berkembang dalam komunitas Sasak.
\end{abstract}

Kata kunci: bandingan geografis, sastra, variasi 


\section{Pendahuluan}

Masyarakat yang mendiami wilayahwilayah Provinsi Nusa Tenggara Barat sangat majemuk. Pulau Lombok didiami oleh empat suku bangsa yang besar, di samping berbagai kelompok suku bangsa dan bangsa pendatang baru. Keempat suku tersebut adalah suku bangsa Sasak, Bima, Sumbawa, dan suku bangsa Bali. Keberadaan masing-masing komunitas ditandai oleh identitas yang berbeda, yang salah satunya berwujud bahasa dan kesastraan. Dapat dikatakan bahwa setiap daerah yang mempunyai bahasa daerah sangat mungkin mempunyai sastra daerah (Tuloli, 1991:1).

Suku bangsa Bali telah mendiami Pulau Lombok pada sekitar abad 17 sampai 19. Keberadaan mereka di Lombok ditunjang juga dengan jarak Pulau Bali dan Lombok yang hanya dibatasi oleh Selat Lombok. Keberadaan suku Bali di Lombok ini memperkaya khazanah kesastraan Lombok dengan dibawanya sastra Bali ke Lombok oleh pendatang-pendatang dari Bali tersebut.

Kehidupan masyarakat Bali di Lombok dewasa ini, merupakan kesinambungan sosial budaya yang berasal dari masa lalu, yakni dari zaman prasejarah, yaitu zaman prahindu-budha. Dengan demikian, hal ini berarti kebudayaan Bali dewasa ini adalah produk suatu proses sejarah yang panjang yang dialami oleh masyarakatnya. Adanya lingkungan sosial budaya dan kondisi geografis yang berbeda dengan daerah asal secara otomatis akan memunculkan adanya saling pengaruh antara masyarakat pendatang dengan masyarakat asli daerah yang didatangi. Selain perbedaan sosial budaya, kondisi geografis yang berbeda menuntut masyarakat pendatang untuk menyesuaikan diri dengan keadaan geografis wilayah yang ditempati. Adanya proses adaptasi ini, dalam jangka waktu yang lama, akan memunculkan variasi-variasi sebagai hasil adaptasi. Proses adaptasi ini juga akan memunculkan variasi dalam karya sastra. Hal ini dikarenakan sastra merupakan salah satu wujud hasil budaya manusia. Perbedaan kondisi sosial budaya dan geografis yang berbeda, sedikit banyak juga akan diikuti pula dengan perubahan wujud sastra, artinya variasi sosial budaya dan kondisi geografis akan diikuti pula dengan munculnya variasi sastra. Dengan melakukan kajian bandingan geografis diharapkan dapat diperoleh gambaran wujud kontak sastra Bali selama masa perjalanannya dalam komunitas Sasak.

\section{Kerangka Teori}

Kajian sastra bandingan adalah pendekatan ilmu sastra yang tidak menggunakan teori sendiri. Dalam kajian ini, teori apapun dapat dimanfaatkan sesuai dengan objek dan tujuan penelitiannya. Dalam kajian sastra bandingan, metode perbandingan adalah yang utama. Dengan demikian uraian yang dilakukan dalam sastra bandingan berlandaskan pada azas banding membandingkan (Djoko Damono, 2005). Remak (1990:1) menyebutkan bahwa sastra bandingan adalah kajian sastra di luar batas sebuah negara dan kajian hubungan di antara sastra dengan bidang alam serta kepercayaan yang lain seperti seni (misalnya seni tari, seni musik, seni patung/pahat, di samping filsafat, sejarah, dan ilmu sosial). Menurut Remak secara ringkas yang dilakukan dalam sastra bandingan adalah membandingkan sastra sebuah negara dengan sastra negara lain dan membandingkan sastra dengan bidang lain sehingga mencerminkan keseluruhan ungkapan kehidupan. Sementara itu, Nada (1999:9) menyatakan bahwa sastra bandingan adalah suatu studi atau kajian sastra suatu bangsa yang mempunyai kaitan kesejarahan dengan sastra bangsa lainnya, bagaimana terjalin proses saling mempengaruhi antara satu dengan lainnya, apa yang telah diambil suatu sastra, dan apa pula yang telah disumbangkannya. Nada 
membuat studi mengenai proses perpindahan sastra dari satu daerah ke daerah lain, hal-hal yang menyangkut berbagai segi tematik dan stikistik seperti tipe, diksi, dan gaya. Menurut Nada, hal penting dalam studi sastra bandingan adalah perbedaan bahasa. Pendapat lain mengatakan bahwa sastra bandingan menyurvai pertukaran gagasan, tema, buku atau perasaan di antara bangsa-bangsa, di antara dua atau beberapa sastra. Sastra bandingan merupakan studi sembarang gejala sastra dari perspektif lebih dari satu sastra suatu bangsa atau dalam hubungannya dengan suatu atau bahkan dengan beberapa disiplin intelektual. Dari berbagai definisi yang dikemukakan diatas, dapat disimpulkan bahwa dalam kajian sastra bandingan, metode perbandingan adalah yang utama.

Objek yang dibandingkan dapat berupa sastra dengan sastra, sastra dengan bidang seni lainnya, maupun sastra dengan bidang keilmuan lain. Aspek-aspek yang dibandingkan dapat berupa genre dan bentuk, periode, aliran, dan pengaruh, serta tema dan mitos. Akan tetapi, kajian sastra bandingan tentu saja tidak sebatas pada halhal di atas, kajian sastra bandingan dapat dikembangkan sesuai dengan objek dan tujuan penelitian.

Salah satu studi sastra bandingan yang dapat dilakukan adalah studi sastra bandingan geografis. Kajian sastra bandingan geografis dalam kajian ini mengacu kepada perbandingan jenis dan ragam sastra yang sama dan berasal dari daerah yang sama, dalam suatu kurun waktu tertentu, yang berkembang di suatu wilayah yang berbeda. Kajian ini membandingkan ragam dan jenis karya sastra Bali yang tumbuh dan berkembang di Pulau Bali dan Pulau Lombok, dalam suatu kurun waktu tertentu. Pulau Bali dan Pulau Lombok merupakan sebuah wilayah yang secara geografis dan sosial budaya berbeda. Perbedaan kondisi sosial budaya dan geografis yang berbeda, sedikit banyak juga akan diikuti pula dengan perubahan wujud sastra, artinya variasi sosial budaya dan kondisi geografis akan diikuti pula dengan munculnya variasi sastra.

Dengan melakukan kajian bandingan geografis diharapkan dapat diperoleh gambaran wujud kontak sastra Bali selama masa perjalanannya dalam komunitas Sasak di Pulau Lombok.

\section{Metode Penelitian}

Data karya sastra yang digunakan dalam kajian ini dikumpulkan di enklaveenklave Bali di Pulau Lombok. Damhujin (2005) mengatakan bahwa komunitas Bali yang tinggal di Lombok pada mulanya hanya bermukim di wilayah Cakranegara, Mataram, Pagutan, Pagesangan, dan Pamenang, yang merupakan sisa-sisa wilayah kekuasaan kerajaan Singasari yang mengalami keruntuhan pada abad ke-18. Pada pertengahan abad ke-19, beberapa di antara kelompok penduduk Bali tersebut melakukan persebaran ke arah utara, yaitu daerah Tanjung, dan ke sebelah timur yaitu ke wilayah Kecamatan Bayan. Di samping itu, terjadi persebaran penduduk Bali dari Mataram ke arah timur, ke Desa Peninjauan, Kecamatan Narmada, dan ke wilayah selatan, Desa Pelangan, Kecamatan Sekotong Tengah.

Data yang digunakan yaitu data primer dan data sekunder. Data primer adalah data yang berupa karya sastra. Data ini diperoleh dengan dua cara, yaitu dengan cara studi lapangan, artinya data diperoleh dari lokasi secara langsung, studi pustaka, dan studi katalog, yaitu dengan cara mengumpulkan data-data yang telah terdokumentasi, baik berbentuk rekaman maupun data-data pustaka, yang berupa karya sastra. Studi katalog dilakukan untuk menginventarisasi karya sastra tulis tradisional yang berwujud naskah. 
Data sekunder merupakan data yang tidak berupa karya sastra, tetapi berkaitan erat dengan karya sastra. Data ini dapat berupa penelitian-penelitian tentang karya sastra, kondisi sosial budaya masyarakat pemilik karya sastra, dan sebagainya. Seperti halnya data primer, data sekunder juga dikumpulkan dengan dua cara, yaitu, melalui studi pustaka (library research), dan studi lapangan.

Pengumpulan data di lapangan dilakukan dengan cara mendatangi lokasi penelitian dan mewawancarai narasumber. Mereka yang dijadikan narasumber ini terdiri atas dua kelompok. Kelompok pertama adalah mereka yang termasuk dalam narasumber primer, yaitu pembawa/pencerita karya sastra yang hidup dalam masyarakat penutur bahasa Bali di Lombok, dan kelompok kedua adalah informan yang bukan pembawa/pencerita, mereka terdiri atas golongan-golongan seperti tokoh adat, tokoh pendidik, pemuka masyarakat, dan audiens. Pengumpulan data dilakukan dengan cara perekaman, pencatatan, dan pemotretan. Wawancara dilakukan untuk mendapatkan data dari informan, baik pembawa/pencerita maupun tokoh-tokoh adat, pendidik, pemuka masyarakat, maupun audiens, sedangkan data-data yang berupa perbuatan, reaksi audiens, dan performance dikumpulkan dengan cara pencatatan dan pemotretan.

Data yang didapatkan dari lokasi, selanjutnya diolah dengan melalui tahapan sebagai berikut. Pertama, data-data yang diperoleh dari studi pustaka dan studi katalog diinventarisasi. Kedua, data rekaman ditranskripsikan atau dipindahkan dari bentuk rekaman ke bentuk tulisan. Kegiatan pentranskripsian dilakukan segera setelah perekaman data untuk memperkecil kemungkinan salah dengar. Ketiga, transkripsi yang berupa karya sastra dipisahkan dari transkripsi wawancara dengan informan-informan seperti audiens dan tokoh-tokoh yang lain. Keempat, karya sastra yang telah ditranskripsi diterjemahkan dalam bahasa Indonesia untuk memudahkan pemahaman pembaca. Penerjemahan dilakukan secara terikat agar tidak mengubah struktur asli karya. Kelima, datadata yang telah diolah menjadi data siap pakai kemudian dianalisis dengan menggunakan metode komparatif diakronik untuk menelusuri perubahan dan perkembangan sastra Bali yang hidup dan berkembang dalam komunitas tutur bahasa Sasak.

\section{Pembahasan}

\subsection{Ragam Sastra Sasak}

Bentuk sastra yang hidup di kalangan etnis Sasak berbentuk prosa dan puisi. Ragam sastra Sasak yang berbentuk prosa antara lain adalah legenda, cerita jenaka, fabel, cerita hantu dan raksasa, cerita datu, dan mitos. Legenda merupakan salah satu ragamsastra berbentuk prosa yang menceritakan tentang sejarah atau asal mula suatu tempat, desa, keadaan, maupun suatu kebiasaan

Cerita jenaka lebih mengarah pada cerita yang berkaitan dengan hal-hal yang lucu, bodoh, akal bulus, serta tipu muslihat yang mungkin terjadi dalam kehidupan sehari-hari. Cerita jenaka pada umumnya berfungsi sebagai hiburan dan sangat digemari oleh masyarakat terutama anakanak. Cerita jenaka juga dapat berfungsi sebagai sarana pendidikan karena di balik sifat jenaka tersembunyi sifat didaktis. Cerita ini biasa didongengkan oleh orang tua kepada anaknya sebagai sarana pewarisan nilai-nilai moral dan didaktis.

Fabel merupakan kisah-kisah yang menceritakan dunia binatang. Tokoh-tokoh dalam fable semuanya adalah binatang. Namun demikian, tokoh-tokoh binatang tersebut memerankan watak dan budi manusia. Mereka dilukiskan dapat bercakapcakap dan bertingkah laku, serta berpikir 
selayaknya manusia, bahkan masalah mereka pun tidak jauh berbeda dengan masalah manusia. Oleh karena itu, dalam fabel banyak mengandung falsafah hidup dan banyak pula yang merupakan sindiran terhadap tingkah laku manusia dalam bermasyarakat. Cerita fabel pada umumnya bersifat jenaka dan berfungsi untuk memperhalus sindiran.

Cerita hantu dan raksasa muncul dalam etnis Sasak karena masyarakat Sasak pada umumnya percaya akan adanya mahkluk halus yang dalam bahasa Sasak disebut tuselaq, raksasa, bebodo lambek, bakeq, dan berhala. Tuselaq, bebodo lambek, bakeq, dan berhala digambarkan sebagai mahkluk halus jahat yang suka menyembunyikan anak-anak, menyebabkan anak-anak sakit, dan membawa malapetaka. Raksasa digambarkan sebagai mahkluk jahat bertubuh besar dan berwajah jelek, serta suka makan daging manusia. Bebodo lambek digambarkan sebagai makhluk halus yang mempunyai susu besar dan panjang. Karena anak-anak sering ditakut-takuti oleh orang tuanya dengan cerita hantu-hantu tersebut, dalam imajinasi mereka berkembang keberadaan mahkluk halus tersebut, dan cerita ini kemudian diceritakan juga secara turun temurun kepada anak cucu mereka.

Cerita datu merupakan kisah raja-raja Sasak yang tersebar di Pulau Lombok. Tokoh datu dianggap sebagai tokoh utama dikalangan nenek moyang masyarakat Sasak, dan sering pula dihubungkan dengan mitos roh datu yang menguasai kehidupan manusia.

Mitos merupakan cerita yang dianggap suci dan benar-benar terjadi oleh yang empunya cerita. Mitos ditokohi oleh dewa atau mahkluk setengah dewa. Peristiwanya biasanya terjadi di dunia lain atau di dunia yang bukan seperti yang kita kenal, dan peristiwa terjadi di masa lampau. Mitos pada umumnya mengisahkan terjadinya alam semesta, dunia, manusia pertama, terjadinya maut, bentuk khas binatang, topografi, gejala alam, dan sebagainya. Mitos juga menceritakan tentang petualangan para dewa, kisah percintaan, dan hubungan kekerabatan mereka.

Sedangkan sastra berbentuk puisi yang hidup dalam etnis Sasak antara lain adalah lelakaq, kayaq, pepinja, dan basa beciq. Lelakaq merupakan istilah untuk menyebut ragam sastra pantun dalam etnis Sasak. Berdasarkan isinya lelakaq dapat dibagi menjadi beberapa jenis, antara lain lelakaq penyelemor, nyoake, kasmaran, pepinja, tuduh, sindiran, dan agama. Lelakaq penyelemor merupakan pantun yang berfungsi sebagai hiburan hati yang duka, isinya bersifat jenaka. Lelakaq nyaoke merupakan pantun yang berisi tekad seseorang untuk mengabdi kepada raja. Lelakaq kasmaran berupa pantun yang isinya merupakan curahan hati para muda mudi yang sedang mabuk asmara. Lelakaq pepinja adalah istilah untuk pantun teka-teki dalam etnis Sasak, sedangkan lelakaq tuduh merupakan pantun nasib yang berisi ratapan seseorang yang kecewa karena keinginannya tidak tercapai. Lelakaq sindiran adalah pantun sindiran. Lelakaq agama adalah pantun agama yang berisi nasihat untuk mengerjakan perintah agama.

Basa beciq atau kerante kodeq dalam khazanah sastra lama disebut sebagai mantra. Berdasarkan kegunaannya, dalam etnis Sasak dikenal empat jenis basa beciq, yaitu jejampi, merupakan mantra yang digunakan oleh para dukun, puji merupakan mantra yang digunakan untuk memperoleh kekebalan terhadap senjata tajam danapi, senggeger merupakan mantra pengasihan yang ditujukan kepada orang yang dicintai agar menerima cinta pengirim mantra, dan begik yaitu ilmu hitam yang dipakai untuk mengguna-gunai orang sehingga jatuh sakit. 


\subsection{Ragam Sastra Bali}

Seni sastra adalah salah satu warisan kebudayaan yang luhur di Bali. Ia bukan saja bermutu tinggi, tetapi merupakan referensi, literer, bahkan sumber inspirasi dari bentuk seni lainnya. Wiracarita Ramayana memberi inspirasi timbulnya senipewayangan di Bali; Wiracarita Mahabhrata sumber pengamatan dari berbagai bentuk patung, lukisan, ukiran, dan lain-lainnya.

Sejak zaman dulu masyarakat Bali telah mengenal tulisan Bali, ditulis di atas daun lontar dengan pisau pengutik dan cara itu disebutnya ngropak. Tulisan-tulisan semacam ini juga disimpan di sebuah kotak yang diukir dan dihiasi sangat bagus, yang disebut kropak. Pada mulanya sastra Bali ditulis di atas lempengan tembaga, atau ditatah pada relief-relief candi, serta arcaarca tertentu. Lempengan-lempengan tembaga itu disebut prasasti, dan disimpan di pura-pura. Sampai saat ini banyak pura-pura yang masih menyimpan prasasti-prasasti, diantaranya pura desa Batuan, pura Jogan Agung (Ketewel), pura Sukawana (Bangli), pura Sading (Denpasar), pura Blanjong (Denpasar), dan lain-lainnya. Prasastiprasasti itu memakai bahasa Sansekerta dan bahasa Bali Kuna.Hanya kemudian setelah adanya kontak antara Jawa dan Bali kirakira pada abad ke-10, yaitu dengan terjadinya perkawinan antara Raja Udayana dengan Putri Gunapriyadharmapatni, maka mulailah prasasti-prasasti itu memakai bahasa Jawa Kuna atau bahasa Kawi.

Sesuai dengan pengayoman seni tari, seni tabuh, dan lain-lain di Bali maka perkembangan seni sastra juga lebih banyak diayomi oleh para raja zaman dulu. Seni sastra mendapat pengayoman yang sungguhsungguh, dan banyak pengarang-pengarang yang muncul di zaman raja-raja dulu, dan banyak di antaranya berasal dari keluarga raja atau bangsawan lainnya. Di samping itu, karena sastra dianggapnya satu warisan yang luhur dan suci, maka masyarakat Bali sampai saat ini masih menghormatinya sebagai dewa ilmu pengetahuan yang disebutnya Sang Hyang Aji Saraswati.

Lontar-lontar atau seni sastra ini tiaptiap enam bulan (210 hari) dibuatkan suatu upacara, di mana pada saat itu orang tak boleh menulis ataupun membaca lontar. Dengan pandangan yang mulia ini timbul juga pandangan ajawera, dimana tiap-tiap orang takut kena kutuk jika belum waktunya untuk membaca sebuah lontar. Kini masih banyak lontar-lontar yang tak bisa dibaca karena pandangan tersebut di atas. Lontar itu disucikan, tapi bertuah besar dan bisa mengobati seseorang yang sedang sakit hanya dengan membuat air suci dari lontar tersebut di atas. Diduga ada juga lontar yang mengandung ajaran ilmu kematian, di mana tiap orang tertentu takut membacanya karena lontar itu bisa memberi jalan kepada seseorang yang mau mati. Jadi dengan adanya pandangan tersebut di atas, pada satu pihak terjadilah perkembangan sastra Bali yang lambat, karena orang-orang yang bisa membaca lontar-lontar yang suci itu adalah orang yang telah cukup umur dan memiliki pengetahuan di bidang sastra Bali.

Kemudian setelah zaman modern ini, mulailah masyarakat umum mempelajari warisannya secara merata yaitu berkat prakarsa Parisada Hindu Dharma, menerjemahkan ajaran-ajaran suci, wedaweda ke dalam bahasa Indonesia agar tiap umat mengetahuinya. Tentu dengan ini apresiasi masyarakat terhadap seni sastra Bali akan lebih tebal dan sekaligus menambah rasa cinta mereka terhadap peninggalan kebudayaan yang luhur ini. Usaha yang sama juga dilakukan oleh Universitas Udayana, Kokar, Asti, Gedong Kirtya, dan lembaga lainnya.

Di samping sastra Bali yang sistem pendidikannya merupakan oral tradisi, sistem yang diterapkan dari mulut ke mulut, seni sastra Bali banyak berkaitan dengan 
seni suara Bali yang disebut tembang, misalnya cerita Ramayana ditulis dalam bentuk Kekawin, cerita Malat dalam bentuk Kidung (Sekar Madya), dan seni sastra popular ditulis dalam bentuk-bentuk tembang macapat.

\subsection{Sastra Bali di Pulau Lombok}

Ragam sastra Bali yang ditemukan di Lombok adalah pepaosan, sesonggan, sloka, cicempedan, dan satua. Istilah pepaosan dalam masyarakat Bali digunakan untuk menyebut kegiatan bersastra yang berupa pembacaan lontar. Kegiatan pepaosan yang ditemukan di Lombok sedikit berbeda dari pengertian di atas, karena yang dibaca bukanlah lontar lagi tetapi tembang-tembang yang telah dialihaksarakan dan diketik ulang dalam aksara latin. Hal ini dilakukan karena sangat terbatasnya masyarakat yang memiliki kemampuan membaca aksara-aksara yang digunakan dalam karya-karya lontar yang asli, yang kebanyakan ditulis dalam aksara daerah.

Kegiatan pepaosan ini ditemukan di enklave Bali Lombok yaitu Tanjung dan Gunungsari. Di Tanjung bahkan telah terbentuk dua kelompok (pesantyan) pepaosan. Kelompok ini mengadakan latihan dua kali dalam seminggu. Latihan biasanya dilakukan pada malam hari, karena pada siang harinya para anggota disibukkan dengan kegiatan mencari nafkah. Pada setiap latihan, mereka dibimbing oleh seorang guru. Sang guru ini mendapatkan ilmunya ketika ia menetap di Bali selama dua belas tahun. Sayangnya sampai saat ini hanya satu orang pelatih saja yang ada, karena belum dilakukan regenerasi dan terbatasnya kemampuan individu untuk menjadi pelatih. Karena alasan ini pulalah, tembang-tembang yang dibacakan dalam kegiatan mamebasan ini belum pernah mengalami inovasi apapun. Tembang-tembang yang dilantunkan dalam kegiatan pepaosan ini diambil dari karya sastra lontar yang telah dialihaksarakan dalam huruf latin. Siapapun bisa menjadi anggota sebuah pesantyan pepaosan ini tanpa ada persyaratan khusus. Anggotaanggota pesantyan yang telah terbentuk saat ini berasal dari kalangan yang beragam, mulai dari petani, guru, maupun pegawai pemerintah dan swasta.

Pepaosan biasanya ditampilkan pada saat-saat kegiatan tertentu, misalnya acara pernikahan, upacara kematian, maupun acara hajatan lainnya. Lontar yang dibacakan beraneka ragam, disesuaikan dengan kegiatan yang sedang berlangsung. Pada saat pembacaan lontar berlangsung, semua anggota perkumpulan duduk bersila melingkar. Tembang dinyanyikan bisa dengan cara bersama-sama maupun bergantian, tergantung pada panjang pendeknya lagu. Setiap selesai pelantunan satu bait, biasanya akan diselingi dengan penerjemahan dalam bahasa Sasak maupun bahasa Indonesia. Pemain yang bertugas sebagai penerjemah ini harus menguasai dua bahasa daerah, yaitu bahasa Bali dan bahasa Sasak. Pada setiap pelaksanaan pepaosan biasanya disertai sesajen yang terdiri dari tiga unsur, yaitu air, api, dan bunga. Sesajen ini dimaksudkan untuk melancarkan sampainya doa-doa yang dipanjatkan sebelum pembacaan dimulai. Kegiatan pepaosan ini biasanya diiringi oleh instrumen musik gamelan, seperti gong, canang, saron, dan sebagainya. Penabuh gamelan diambil dari anggota kelompok yang piawai memainkan gamelan.

Sesonggan merupakan salah satu ragam gancaran pralambang, yang dalam khazanah sastra Indonesia sering disebut sebagai pepatah. Dalam masyarakat Bali, dikenal pralambang sesonggan. Sesongan menurut Dananjaya (1991:30-31) disamakan dengan pribahasa sesungguhnya (true proverb) dari jenis yang mempergunakan kalimat sederhana. Sesonggan biasanya disampaikan secara 
tidak disengaja atau sengaja melihat seseorang berbuat kesalahan, lalu menasehatinya dengan pribahasa, atau pada saat memperingatkan seseorang dan menasehati.

Satua adalah cerita rakyat. Cerita rakyat daerah Bali di tengah-tengah kehidupan masyarakat Bali dikenal dengan istilah satua. Istilah satua mengandung pengertian cerita. Cerita rakyat Bali merupakan cerita yang tumbuh dan berkembang turun menurun di tengahtengah kehidupan masyarakat Bali dari generasi ke generasi berikutnya secara lisan dalam versi yang berbeda. Sebagai salah satu bentuk sastra Bali tradisional, satua tersebut mempunyai kedudukan dan peranan penting dalam masyarakat Bali, karena tata nilai yang terkandung di dalamnya berkaitan erat dengan kehidupan masyarakatnya. Dalam kehidupan masyarakat Bali, cerita rakyat ini biasanya disampaikan sebagai dongeng menjelang tidur. Tradisi ini pernah hidup semarak dalam kehidupan mereka, tetapi tradisi itu pada saat ini sudah tidak jelas rimbanya.

Selain sesonggan, jenis pralambang yang lain adalah sloka. Sloka dalam khazanah sastra Indonesia disebut sebagai bidal.

Cicempedan dalam khazanah sastra Indonesia lama dikenal dengan nama tekateki tradisional. Cicempedan ini biasanya disampaikan pada saat senggang seperti pada malam hari ketika berkumpul dengan teman-teman dan pada saat-saat acara tertentu. Tujuannya yaitu menguji kepandaian temannya.

Dari penelitian yang telah dilakukan, ragam dan jenis sastra Bali yang berkembang di Bali dan yang berkembang di enklave Bali di Lombok, secara visual, dapat dilihat dalam tabel di bawah ini.

Tabel 1. Ragam dan Jenis Sastra Bali yang Berkembang di Bali dan Enklave Bali di Lombok

\begin{tabular}{|c|c|c|c|c|c|}
\hline No. & Ragam Sastra Bali & $\begin{array}{l}\text { Ragam Sastra } \\
\text { Enklave } \\
\text { Cakranegara }\end{array}$ & $\begin{array}{l}\text { Ragam Sastra } \\
\text { Enklave Tanjung }\end{array}$ & $\begin{array}{l}\text { Ragam Sastra } \\
\text { Enklave } \\
\text { Peninjauan }\end{array}$ & $\begin{array}{l}\text { Ragam Sastra } \\
\text { Enklave } \\
\text { Gunungsari }\end{array}$ \\
\hline 1. & $\begin{array}{l}\text { Gancaran } \\
\text { a. Ttatwa cerita } \\
\text { b. Pralambang } \\
\text { - Sesonggan } \\
\text { - Sesenggakan } \\
\text { - Wewangsalan } \\
\text { - Sesawangan } \\
\text { - Sloka } \\
\text { - Beblabadan } \\
\text { - Cecimpedan } \\
\text { - Cecangkitan } \\
\text { - Sesimbing } \\
\text { - Cecangkriman } \\
\text { - Raos } \\
\text { - Sipta } \\
\text { - Sesemon } \\
\text { - Peparikan } \\
\text { - Gegendingan }\end{array}$ & $\begin{array}{l}\text { - Sesonggan } \\
\text { - Sloka } \\
\text { - Cicempedan }\end{array}$ & & - Sesonggan & \\
\hline 2. & $\begin{array}{l}\text { Tembang } \\
\text { i. Sekar Rare } \\
\text { - Dolanan } \\
\text { - Jejanggeran } \\
\text { - Gending Sangiang } \\
\text { ii. Sekar Macapat } \\
\text { - Kumambang } \\
\text { - Pucung } \\
\text { - Ginanti } \\
\text { - Mijil }\end{array}$ & $\begin{array}{ll}\text { Sekar Macapat } \\
-\quad \text { Kumambang } \\
-\quad \text { Pucung } \\
-\quad \text { Ginanti } \\
-\quad \text { Mijil }\end{array}$ & $\begin{array}{l}\text { Sekar Macapat } \\
\text { - Kumambang } \\
\text { - Pucung } \\
\text { - Ginanti } \\
\text { - Mijil }\end{array}$ & $\begin{array}{l}\text { Sekar Macapat } \\
\text { - Kumambang } \\
\text { - Pucung } \\
\text { - Ginanti } \\
\text { - Mijil }\end{array}$ & $\begin{array}{l}\text { Sekar Macapat } \\
\text { - Kumambang } \\
\text { - Pucung } \\
\text { - Ginanti } \\
\text { - Mijil }\end{array}$ \\
\hline
\end{tabular}


Karya Sastra yang Tumbuh dan Berkembang ...(Nining Nur Alaini)| 93

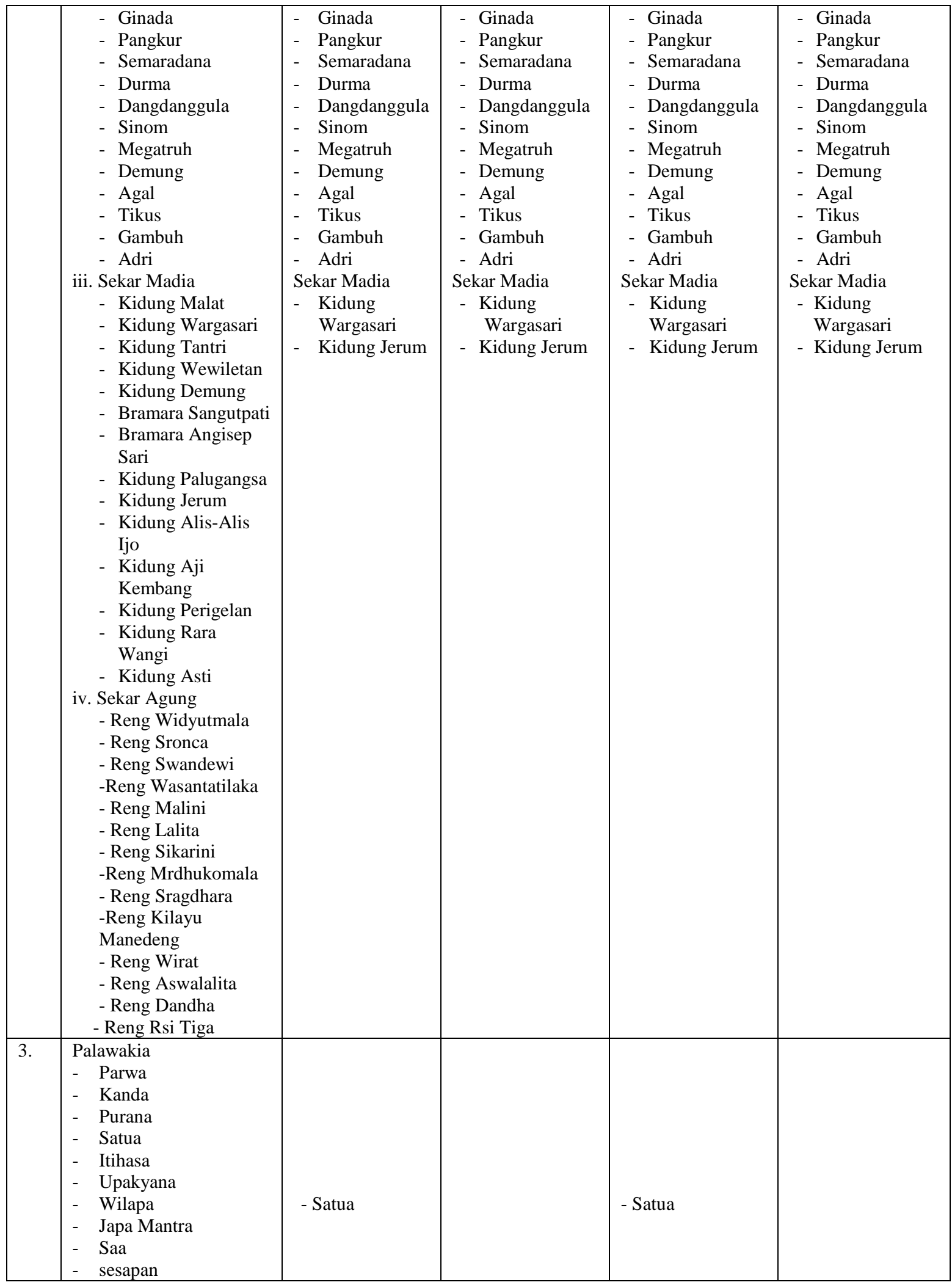

Dari tabel di atas, dapat dilihat bahwa ragam sastra yang masih eksis di semua enklave Bali di Lombok adalah ragam tembang dari jenis tembang macapat atau sekar alit dan sekar madia. Hal ini disebabkan karena tembang-tembang tersebut biasanya dinyanyikan dalam rangka tradisi pepaosan, sebuah tradisi yang sampai 
sekarang masih dijaga kelestariannya baik oleh komunitas Bali di Lombok maupun komunitas Bali di tempat asalnya, yang mereka sebut sebagai mabasan. Pemertahanan tradisi ini memang erat kaitannya dengan upacara keagamaan yang dianut oleh mayoritas komunitas Bali. Selain itu, ragam sastra Bali di Lombok adalah sesonggan, sloka, cicempedan, dan satua.

\subsection{Wilayah Komunitas Sastra Bali yang Inovatif}

Berdasarkan pengamatan dan data di lapangan dapat disimpulkan bahwa di hampir semua enklave Bali di Lombok, ragam-ragam sastra Bali tertentu saja yang masih hidup. Pepaosan atau yang di Bali disebut dengan mabebasan merupakan satusatunya ragam sastra yang masih eksis di semua enklave Bali di Lombok. Berdasarkan data yang diperoleh di lapangan, jenis tembang yang dinyanyikan dalam tradisi pepaosan tidak mengalami perubahan. Berdasarkan informasi yang diperoleh dari informan, hal ini disebabkan karena belum ada di antara mereka yang memiliki kemampuan untuk mengubah tembang, dan ragam sastra tembang ini memang telah memiliki aturan yang telah disepakati. Hal lainnya adalah tradisi pepaosan ini sangat erat kaitannya dengan upacara keagamaan, sehingga ragam sastra yang terlibat di dalamnya akan dianggap sebagai sastra sakral oleh komunitasnya.
Kesakralan ini merupakan salah satu alasan untuk tetap mempertahankan bentuk asli sastra tersebut. Perbandingan-perbandingan ragam sastra Bali yang terdapat di enklave Lombok dapat dilihat di bawah ini.

\subsubsection{Ragam Tembang}

Tembang dalam tradisi bersastra komunitas Bali ditampilkan dalam pertunjukan pepaosan. Tembang dalam khazanah sastra Bali dibedakan menjadi empat jenis, yaitu: 1) sekar rare, 2) sekar macapat (sekar alit), 3) sekar madia (kekidungan $=$ tembang tengahan), dan 4) sekar agung.

Tembang-tembang yang digunakan oleh pesantyan-pesantyan komunitas Bali di Sasak hanya jenis sekar macapat (alit) dan sekar madia (kekidungan). Sekar macapat dalam khazanah kesastraan Bali terdiri dari pupuh-pupuh sinom, ginada, ginanti, mijil, pucung, kumambang, semarandana, dangdang, durma, pangkur, gambuh, demung, adri, megatruh, dan tikus kapanting, sedangkan sekar madia dibedakan menjadi kidung wargasari - dewa yajna, kidung wilet mayura - rsi yajna, kidung tantri - manusa yajna, kidung aji kembang - pitra yajna, kidung alis-alis ijo bhuta yajna.

Dari ragam-ragam sekar di atas, pupuh tikus kapanting tidak ditemukan diempat enklave Bali di Lombok.

Tabel 2.Ragam Tembang pada Komunitas Bali di Bali dan Komunitas Bali di Lombok

\begin{tabular}{|l|c|c|c|c|}
\hline & \multicolumn{2}{|c|}{ Bali } & \multicolumn{2}{c|}{ Bali di Lombok } \\
\hline Pupuh & Guru Lagu/ & Contoh Tembang & Guru & Contoh Tembang \\
& Guru & & Lagu/ & Guru \\
& Wilangan & & Wilangan & \\
& & & \\
\hline
\end{tabular}


Karya Sastra yang Tumbuh dan Berkembang ...(Nining Nur Alaini)| 95

\begin{tabular}{|c|c|c|c|c|}
\hline Sinom & $\begin{array}{l}8 \mathrm{a} \\
8 \mathrm{i} \\
8 \mathrm{a} \\
8 \mathrm{i} \\
8 \mathrm{i} \\
8 \mathrm{u} \\
8 \mathrm{a} \\
8 \mathrm{i} \\
4 \mathrm{u} \\
8 \mathrm{a}\end{array}$ & $\begin{array}{l}\text { Susilane utamayang } \\
\text { Satiane anggen ngembanin } \\
\text { Keto munggah di agama } \\
\text { Kukuhang mangdennya pasti } \\
\text { Eda mamuikin aji } \\
\text { Ida sungsung maka guru } \\
\text { Sueca ngicen karahayuan } \\
\text { Tunasin pangalang ati } \\
\text { Maka suluh } \\
\text { Gigisan paling di jalan }\end{array}$ & $\begin{array}{l}8 \mathrm{a} \\
8 \mathrm{i} \\
8 \mathrm{a} \\
8 \mathrm{i} \\
8 \mathrm{i} \\
8 \mathrm{u} \\
8 \mathrm{a} \\
8 \mathrm{i} \\
4 \mathrm{u} \\
8 \mathrm{a}\end{array}$ & $\begin{array}{l}\text { Sampun rawuh ring paseban, } \\
\text { Sang kalih malinggih cepil, } \\
\text { Tan suwe resi Sudhanta, } \\
\text { Ngebah lawang raris mijil, } \\
\text { Sang kalih pada nganjali, } \\
\text { Dang guru sampun malungguh, } \\
\text { Sambil knyung mangandika, } \\
\text { Mangkin bapa mangawitin, } \\
\text { Pacang nyambung, } \\
\text { Dharmaning sampun grehasta. }\end{array}$ \\
\hline Ginada & $\begin{array}{c}8 \mathrm{a} \\
8 \mathrm{i} \\
8 \mathrm{a} / \mathrm{o} \\
8 \mathrm{u} \\
8 \mathrm{a} \\
4 \mathrm{i} \\
8 \mathrm{a}\end{array}$ & $\begin{array}{l}\text { I jayaprana angucap } \\
\text { Lamun tuduh beli mati } \\
\text { Dija ko beli manongos } \\
\text { Yadian ko magedong batu } \\
\text { Lamun suba janji pejah } \\
\text { Mangenmasin } \\
\text { Nanging patute tindihang }\end{array}$ & $\begin{array}{l}8 \mathrm{a} \\
8 \mathrm{i} \\
8 \mathrm{a} \\
8 \mathrm{u} \\
8 \mathrm{a} \\
4 \mathrm{i} \\
8 \mathrm{a}\end{array}$ & $\begin{array}{l}\text { Sangkalih raris memarga, } \\
\text { nyudi linggih mahayati, } \\
\text { kadi Ratih lawan Smara, } \\
\text { tangkil ring Bhataraguru, } \\
\text { nuna guna kama tantra, } \\
\text { kanggen ngabih, } \\
\text { kahayon miwah kawidnyan. }\end{array}$ \\
\hline Ginanti & $\begin{array}{l}8 \mathrm{u} \\
8 \mathrm{i} \\
8 \mathrm{a} \\
8 \mathrm{i} \\
8 \mathrm{a} \\
8 \mathrm{i}\end{array}$ & $\begin{array}{l}\text { Mirib suba liu tau } \\
\text { Kadine munggah ring aji } \\
\text { Jatin sengsara punika } \\
\text { Wetu saking tingkah pelih } \\
\text { Pelih saking katambetan } \\
\text { Tambet dadi dasar sedih }\end{array}$ & $\begin{array}{r}8 \mathrm{u} \\
8 \mathrm{i} \\
8 \mathrm{a} \\
8 \mathrm{i} \\
8 \mathrm{a} \\
8 \mathrm{i}\end{array}$ & $\begin{array}{l}\text { Mirib suba tatas tau, } \\
\text { ring abah sang Widyasari, } \\
\text { kala ngiringang grehasta, } \\
\text { panuntun maguru bakti, } \\
\text { caluhang sadina dina, } \\
\text { ulengangring Sanghyang Widhi. }\end{array}$ \\
\hline Mijil & $\begin{array}{l}4 \mathrm{u} \\
6 \mathrm{i} \\
6 \mathrm{o} \\
4 \mathrm{e} \\
6 \mathrm{e} \\
4 \mathrm{u} \\
6 \mathrm{i} \\
6 \mathrm{i} \\
8 \mathrm{u}\end{array}$ & $\begin{array}{l}\text { Salah unduk } \\
\text { Nista iba sampi } \\
\text { Jugul ditu nongos } \\
\text { Awak gede } \\
\text { Tanduk lanying ngrenyeb } \\
\text { Nging mategul } \\
\text { Nyurudayu sai } \\
\text { Kone iba sakti } \\
\text { Tan padaya mredi idup }\end{array}$ & $\begin{array}{l}4 \mathrm{u} \\
6 \mathrm{i} \\
6 \mathrm{o} \\
4 \mathrm{i} \\
6 \mathrm{e} \\
4 \mathrm{i} \\
6 \mathrm{i} \\
6 \mathrm{i} \\
8 \mathrm{u}\end{array}$ & $\begin{array}{l}\text { Doning sampun, } \\
\text { Pada puput mukti, } \\
\text { Bekelang ngerawos, } \\
\text { Kala wengi, } \\
\text { Ngantosang kiyape, } \\
\text { Melah jani, } \\
\text { Becikang malinggih, } \\
\text { Bapa pacang nyawis, } \\
\text { Pitaken cening iwau. }\end{array}$ \\
\hline Pucung & $\begin{array}{l}4 \mathrm{u} \\
8 \mathrm{u} \\
6 \mathrm{a} \\
8 \mathrm{i} \\
4 \mathrm{u} \\
8 \mathrm{a}\end{array}$ & $\begin{array}{l}\text { Pupuh Pucung } \\
\text { Anggon jalaran manutur } \\
\text { Cening pianak bapa } \\
\text { Mungpung Cening enu cenik } \\
\text { Apung suluk } \\
\text { Jemet mlajahang awak }\end{array}$ & $\begin{array}{l}4 \mathrm{u} \\
8 \mathrm{u} \\
6 \mathrm{a} \\
8 \mathrm{i} \\
4 \mathrm{u} \\
8 \mathrm{a}\end{array}$ & $\begin{array}{l}\text { Nuli nyambung, } \\
\text { Sang jayapurusa matur, } \\
\text { Cingak baktin tityang, } \\
\text { Sang loba nunas pawisik, } \\
\text { Ring iratu, } \\
\text { Sang dana sugih ring tatwa. }\end{array}$ \\
\hline Kumambang & $\begin{array}{l}4 \mathrm{a} \\
8 \mathrm{i} \\
6 \mathrm{a} \\
8 \mathrm{i} \\
8 \mathrm{a}\end{array}$ & $\begin{array}{l}\text { Dados jadma } \\
\text { Jatin ipun pinih luih } \\
\text { Patut ngayu bagia } \\
\text { Yadin lacur turin bengil } \\
\text { Sida pacang mangguh bagia }\end{array}$ & $\begin{array}{l}4 \mathrm{a} \\
8 \mathrm{i} \\
6 \mathrm{a} \\
8 \mathrm{i} \\
8 \mathrm{a}\end{array}$ & $\begin{array}{l}\text { Tejan surya, } \\
\text { Ngentak sakeng semeng mijil, } \\
\text { Ngawe raga lara, } \\
\text { Sayan sore sayan etis, } \\
\text { Sat amreta nyiram lara. }\end{array}$ \\
\hline Semarandana & $\begin{array}{c}8 \mathrm{i} \\
8 \mathrm{a} \\
8 \mathrm{e} / \mathrm{o} \\
8 \mathrm{a} \\
8 \mathrm{a} \\
8 \mathrm{u} \\
8 \mathrm{a}\end{array}$ & $\begin{array}{l}\text { Mamisuna ngawe pati } \\
\text { miwah sane lian-lianan } \\
\text { Kancan laksanane kaon } \\
\text { Nyandang pisan 'nto impasang } \\
\text { Mangda Cening tan kasepan } \\
\text { Ngungsi sila sane patut } \\
\text { Darma sadu maring jagat }\end{array}$ & $\begin{array}{l}8 \mathrm{i} \\
8 \mathrm{a} \\
8 \mathrm{o} \\
8 \mathrm{a} \\
8 \mathrm{a} \\
8 \mathrm{u} \\
8 \mathrm{a}\end{array}$ & $\begin{array}{l}\text { Awinan patut apikin, } \\
\text { Hidupe ring Lokasraya, } \\
\text { Nabnab manah mangda katon, } \\
\text { Ring tingkahe ngarap dharma, } \\
\text { Bebas sakeng dosa maya, } \\
\text { Ento anggen ngalih nau, } \\
\text { Mupu hidup jati bagya. }\end{array}$ \\
\hline Dangdang & $\begin{array}{c}10 \mathrm{i} \\
4 \mathrm{a} \\
6 \mathrm{a} \\
8 \mathrm{i} / \mathrm{e} \\
8 \mathrm{u} \\
8 \mathrm{i} \\
8 \mathrm{a} \\
8 \mathrm{u} \\
8 \mathrm{a} \\
8 \mathrm{a} \\
8 \mathrm{i} \\
8 \mathrm{a}\end{array}$ & $\begin{array}{l}\text { Titiang takut kena munyi manis } \\
\text { Ngaku tresna } \\
\text { Gampang nagih nadtad } \\
\text { Anak eluh uli dini } \\
\text { Batangin selaka siu } \\
\text { Joh para bakatang Beli } \\
\text { Saling ke baan kemikan } \\
\text { Makemulan galir bungut } \\
\text { Dija pacang saup jemak } \\
\text { Tuyub ngucap } \\
\text { Adayan suba manengil } \\
\text { Keh manundun dakin basang }\end{array}$ & $\begin{array}{l}12 \mathrm{i} \\
4 \mathrm{a} \\
6 \mathrm{a} \\
8 \mathrm{i} \\
8 \mathrm{u} \\
8 \mathrm{i} \\
8 \mathrm{a} \\
8 \mathrm{u} \\
8 \mathrm{a} \\
8 \mathrm{a} \\
8 \mathrm{i} \\
8 \mathrm{a}\end{array}$ & $\begin{array}{l}\text { Kancit mangkin gelis rauh sang } \\
\text { memargi, } \\
\text { ring jabayan, } \\
\text { pamedal pasraman, } \\
\text { makanten sakadi sedih, } \\
\text { asing pangguh meneng patuh, } \\
\text { tan wenten nyapa sang tangkil, } \\
\text { sarwa tetanduran sekar, } \\
\text { kadi milu sedih luru, } \\
\text { masahsah tiba ring lemah, } \\
\text { bela jengah, } \\
\text { matindih ring Widyasari, } \\
\text { sungsut iseng tinggal priya. }\end{array}$ \\
\hline
\end{tabular}


96|Mabasan, Vol. 7 No. 2, Juli-Desember 2013:85-99

\begin{tabular}{|c|c|c|c|c|}
\hline Durma & $\begin{array}{l}12 \mathrm{a} \\
7 \mathrm{i} \\
6 \mathrm{a} \\
8 \mathrm{a} \\
8 \mathrm{i} \\
5 \mathrm{a} \\
7 \mathrm{i}\end{array}$ & $\begin{array}{l}\text { Da mamadat, mamotoh } \\
\text { mangutang-ngutang } \\
\text { Da ngadu daya lengit } \\
\text { Solah apang melah } \\
\text { Mabanjar mapisaga } \\
\text { Eda maguunin rusit } \\
\text { Astiti ring Hyang } \\
\text { Bakti ngayah ring Gusti }\end{array}$ & $\begin{array}{l}12 \mathrm{a} \\
8 \mathrm{i} \\
6 \mathrm{a} \\
8 \mathrm{a} \\
8 \mathrm{i} \\
4 \mathrm{a} \\
8 \mathrm{i}\end{array}$ & $\begin{array}{l}\text { Gung aksama antuk langgya tityang } \\
\text { nyelag, } \\
\text { matur ring sang maha resi, } \\
\text { midartayang satwa, } \\
\text { nyaritayang sang Lubdaka, } \\
\text { masolah memati mati, } \\
\text { sida ruat, } \\
\text { antuk sang Hyang Shiwa Asih. }\end{array}$ \\
\hline Pangkur & $\begin{array}{c}8 \mathrm{a} \\
11 \mathrm{i} \\
8 \mathrm{u} \\
8 \mathrm{a} \\
12 \mathrm{u} \\
8 \mathrm{a} \\
8 \mathrm{i}\end{array}$ & $\begin{array}{l}\text { Nunas agung sinampura } \\
\text { Ratu titiang ring Ida dane sami } \\
\text { Ngerencana ngawe kidung } \\
\text { Pangkure anggon tembang } \\
\text { Mapi ririh, belog pongah sipok } \\
\text { sigug } \\
\text { Tuara jengah kakedekang } \\
\text { Ngulahang payu mangawi } \\
\end{array}$ & $\begin{array}{c}8 \mathrm{a} \\
11 \mathrm{i} \\
8 \mathrm{u} \\
8 \mathrm{a} \\
12 \mathrm{u} \\
8 \mathrm{a} \\
8 \mathrm{i}\end{array}$ & $\begin{array}{l}\text { Mated bawos sang Sudhanta, } \\
\text { Sang Jayapurusa sarng Widyasari, } \\
\text { sinarengan ida matur, } \\
\text { nyakupang tangan nyuksema, } \\
\text { raris lebar sakeng bale sabha } \\
\text { sampun, } \\
\text { Sang Sudhanta ngapuriang, } \\
\text { sang kalih kajaba raris. }\end{array}$ \\
\hline Gambuh & $\begin{array}{c}\mathrm{u} \\
10 \mathrm{u} \\
12 \mathrm{i} \\
8 \mathrm{u} \\
8 \mathrm{o}\end{array}$ & $\begin{array}{l}\text { Salinin tembang gambuh } \\
\text { Gending Jawi Bali basan ipun } \\
\text { Manuturang ne mawasta asta } \\
\text { Dewi } \\
\text { Cacakan ipun akutus } \\
\text { Mamingunangang manah belog }\end{array}$ & $\begin{array}{c}7 \mathrm{u} \\
10 \mathrm{u} \\
12 \mathrm{i} \\
8 \mathrm{u} \\
8 \mathrm{o}\end{array}$ & \\
\hline Demung & $\begin{array}{l}8 \mathrm{i} \\
4 \mathrm{a} \\
8 \mathrm{u} \\
6 \mathrm{u} \\
8 \mathrm{i} \\
8 \mathrm{a} \\
8 \mathrm{u} \\
6 \mathrm{a} \\
8 \mathrm{i} \\
8 \mathrm{a} \\
8 \mathrm{u}\end{array}$ & $\begin{array}{l}\text { Sesanan i pianak yukti } \\
\text { Ne utama } \\
\text { Nganutin pangajah guru } \\
\text { Kocap ne tetelu } \\
\text { Guru rupaka makadi } \\
\text { Kalih guru pangajian } \\
\text { Guru wisesa ping telu } \\
\text { Punika elingang } \\
\text { Resep-resepang di ati } \\
\text { Linggayang sajroning tuas } \\
\text { Mangdene sadia rahayu }\end{array}$ & $\begin{array}{l}8 \mathrm{i} \\
4 \mathrm{a} \\
8 \mathrm{u} \\
6 \mathrm{u} \\
8 \mathrm{i} \\
8 \mathrm{a} \\
8 \mathrm{u} \\
6 \mathrm{a} \\
8 \mathrm{i} \\
8 \mathrm{a} \\
8 \mathrm{u}\end{array}$ & \\
\hline Adri & $\begin{array}{c}10 \mathrm{u} \\
6 \mathrm{e} \\
8 \mathrm{i} \\
8 \mathrm{u} \\
8 \mathrm{u} \\
8 \mathrm{a} / \mathrm{e} / \mathrm{o} \\
8 \mathrm{u} \\
8 \mathrm{a} \\
8 \mathrm{a}\end{array}$ & $\begin{array}{l}\text { Janten sengka ngardi ne rahayu } \\
\text { Ban kosek manahe } \\
\text { Tuara kena ban ngutungin } \\
\text { Ngelingin ne jati patut } \\
\text { Sajroning jagate biur } \\
\text { Lekahan kaliyuga } \\
\text { Pamtute wetu bingung } \\
\text { Sangiang Dharma ngiring } \\
\text { remba } \\
\text { 'nggen munah watek durjana }\end{array}$ & $\begin{array}{l}8 \mathrm{u} \\
6 \mathrm{a} \\
8 \mathrm{i} \\
8 \mathrm{u} \\
8 \mathrm{u} \\
8 \mathrm{a} \\
8 \mathrm{u} \\
8 \mathrm{a} \\
8 \mathrm{a}\end{array}$ & $\begin{array}{l}\text { Om ksama pujaninghulun, } \\
\text { Yan ati wimudha, } \\
\text { Pralangghya sunga pamuji, } \\
\text { Ri pada sang hyang sinuhun, } \\
\text { Tan pamantra tan pasantun, } \\
\text { Hina rikaya wak manah, } \\
\text { Nging shradha bakti panungsung, } \\
\text { Nugraha ring nis sahaya, } \\
\text { Wineh salwirning sinadhya. }\end{array}$ \\
\hline Magatruh & $\begin{array}{c}12 \mathrm{u} \\
8 \mathrm{i} \\
8 \mathrm{u} \\
8 \mathrm{i} \\
8 \mathrm{o}\end{array}$ & $\begin{array}{l}\text { Krana sengka ngelingin ne jati } \\
\text { patut } \\
\text { Yan ne dini durung pasti } \\
\text { Upami mapikat puuh } \\
\text { Ngaba papikat lelipi } \\
\text { Bin pidan bakat ban mongkos }\end{array}$ & $\begin{array}{l}12 \mathrm{u} \\
8 \mathrm{i} \\
8 \mathrm{u} \\
8 \mathrm{i} \\
8 \mathrm{o}\end{array}$ & \\
\hline $\begin{array}{l}\text { Tikus } \\
\text { Kapanting }\end{array}$ & $\begin{array}{l}8 \mathrm{u} \\
8 \mathrm{i} \\
8 \mathrm{a} \\
8 \mathrm{u} \\
8 \mathrm{a} \\
8 \mathrm{i} \\
8 \mathrm{u} \\
8 \mathrm{i}\end{array}$ & $\begin{array}{l}\text { Yan sira guna amacul } \\
\text { Ingsun warahana yayi } \\
\text { Ala ayunikang lampah } \\
\text { wenten ne ring sastran ipun } \\
\text { Ring wariga kawruhana } \\
\text { Saptawara araneki } \\
\text { Dite soca ya tinandur } \\
\text { Coma bungkahe tanemin }\end{array}$ & $\begin{array}{l}8 \mathrm{u} \\
8 \mathrm{i} \\
8 \mathrm{a} \\
8 \mathrm{u} \\
8 \mathrm{a} \\
8 \mathrm{i} \\
8 \mathrm{u} \\
8 \mathrm{i}\end{array}$ & \\
\hline
\end{tabular}


Dari tabel di atas, dapat disimpulkan bahwa ragam tembang ini tidak mengalami inovasi, baik yang berupa penambahan maupun pengurangan. Hal ini disebabkan karena ragam tembang merupakan ragam sastra yang terikat bentuknya dan telah mempunyai aturan-aturan penulisan yang mantap. Faktor lain yang menyebabkan ragamini tidak mengalami perubahan adalah karena ragam sastra ini dalam komunitas Bali memiliki fungsi sosial yang sakral, yakni sebagai sarana upacara keagamaan, sehingga perubahan yang terjadi dianggap sebagai suatu kesalahan. Perbedaanperbedaan yang terdapat pada tembang lebih disebabkan karena kekurangahlian pencipta tembang.

\subsubsection{Ragam Palawakia}

Ragam sastra palawakia yang terdapat di wilayah enklave Bali di Lombok yang ditemukan adalah jenis satua atau cerita rakyat. Perbandingan ragam sastra palawakia jenis satua di Bali dan enklave Bali di Lombok dapat dilihat dalam tabel di bawah ini.

Tabel 3. Ragam Sastra Palawakia Jenis Satua Sasak, Bali, dan Enklave Bali di Lombok

\begin{tabular}{|l|l|l|}
\hline \multicolumn{1}{|c|}{ Cerita Rakyat Sasak } & \multicolumn{1}{|c|}{ Cerita Rakyat Bali } & \multicolumn{1}{c|}{ Cerita Rakyat Data } \\
\hline $\begin{array}{l}\text { Si Siput Berlomba dengan Si } \\
\text { Harimau }\end{array}$ & Cerita I Kidang dan I Cekcek & Cerita I Kidang dan I Cekcek \\
\hline Loq Sekeq & Cerita I Belog & Cerita I Belog \\
\hline- & - & Cerita I Baluan \\
\hline- & Cerita Siap Badeng & I Siap Selem \\
\hline
\end{tabular}

Tabel 4. Perbandingan Ragam Sastra Cerita Rakyat Sasak, Bali, dan Enklave Bali di Lombok

\begin{tabular}{|l|l|l|l|l|}
\hline No. & \multicolumn{1}{|c|}{ Judul Cerita } & \multicolumn{1}{|c|}{ Motif } & \multicolumn{1}{c|}{ Tokoh } & Klasifikasi \\
\hline \multirow{2}{*}{. } & $\begin{array}{l}\text { Si Siput Berlomba dengan Si } \\
\text { Harimau (Sasak) }\end{array}$ & $\begin{array}{l}\text { Kecerdikan mengalahkan } \\
\text { kekuatan }\end{array}$ & Siput, Harimau & Fabel \\
\cline { 2 - 5 } & $\begin{array}{l}\text { Cerita I Kidang dan I Cekcek } \\
\text { (Narmada) }\end{array}$ & $\begin{array}{l}\text { Kecerdikan mengalahkan } \\
\text { kekuatan }\end{array}$ & I Kidang, I Cekcek & Fabel \\
\cline { 2 - 5 } & $\begin{array}{l}\text { Cerita I Kidang dan I Cekcek } \\
\text { (Bali) }\end{array}$ & $\begin{array}{l}\text { Kecerdikan mengalahkan } \\
\text { kekuatan }\end{array}$ & I Kidang, I Cekcek & Fabel \\
\hline \multirow{2}{*}{2.} & Loq Sekeq (Sasak) & Kebodohan membawa petaka & Loq Sekeq & Dongeng \\
\cline { 2 - 6 } & Cerita I Belog (Bali) & Kebodohan membawa petaka & I Belog & Dongeng \\
\cline { 2 - 5 } & Cerita I Belog (Narmada) & Kebodohan membawa petaka & I Belog & - \\
\hline \multirow{3}{*}{3.} & (Sasak) & - & - & Fabel \\
\cline { 2 - 5 } & Cerita Siap Badeng (Bali) & $\begin{array}{l}\text { Akal dan kecerdikan untuk } \\
\text { menghadapi kekuatan }\end{array}$ & $\begin{array}{l}\text { Siap Badeng, I Kolagan, } \\
\text { Men Kuwuk }\end{array}$ & Fabel \\
\cline { 2 - 5 } & I Siap Selem (Narmada) & $\begin{array}{l}\text { Akal dan kecerdikan untuk } \\
\text { menghadapi kekuatan }\end{array}$ & $\begin{array}{l}\text { I Siap Selem, Musang, } \\
\text { Si Bungsu }\end{array}$ & Fabel \\
\hline
\end{tabular}

Dari tabel di atas, dapat dilihat bahwa cerita yang ditemukan di semua lokasi adalah cerita I Belog. Cerita ini di semua lokasi tidak terdapat perbedaan. Berdasarkan data yang diperoleh dari penelitian I Made Subandia, dkk (2005), cerita I Belog ini merupakan cerita yang popular di Bali.Cerita ini mengisahkan tentang seseorang yang sangat bodoh, sehingga karena kebodohannya ini, ia kehilangan nyawanya. Kronikal cerita tentang kebodohan seseorang yang mengakibatkan ia kehilangan nyawanya ini, selain dikenal di
Bali dan Lombok juga ditemukan di Jawa dalam cerita yang berjudul "Joko Bodo". Alur cerita antara I Belog dan Joko Bodo sama, perbedaan hanya terdapat pada variasi peristiwa, penokohan, dan seting cerita.

Cerita rakyat lain yang mengalami perubahan dari asalnya adalah cerita I Siap Selem yang ditemukan di Narmada. Di Bali cerita serupa cerita ini adalah I Siap Badeng.Alur cerita antara keduanya sama. Perbedaan antara cerita ini terdapat pada nama tokoh, yaitu I Siap Badeng, Men Kuwuk, dan I Kolagan di Bali, dan I Siap 
Selem, Musang, dan Si Bungsu di Narmada. Akhir cerita dalam cerita I Siap Badeng adalah ketika I Kolagan telah tumbuh bulu sayapnya, ia menipu Men Kuwuk dengan cara membuat keributan di sarang, sehingga Men Kuwuk membuka sarang tersebut dan terbanglah I Kolagan menemui ibu dan saudara-saudaranya. Sementara itu, tipu muslihat yang dilakukan oleh Si Bungsu dalam cerita I Siap Selem adalah dengan carameminta Musang untuk melempar tubuhnya ke atas untuk melihat apakah ia sudah cukup gemuk untuk dimakan, setelah lemparan yang dilakukan oleh Musang cukup tinggi terbanglah $\mathrm{Si}$ Bungsu menyeberang sungai menemui induk dan saudara-saudaranya.

Terjadinya perubahan-perubahan ini sangat berkaitan dengan perbedaan sosial budaya dan geografis antara Pulau Lombok dan Bali. Untuk menarik kesimpulan yang tepat terhadap fenomena ini diperlukan penelitian yang lebih mendalam.

\section{Penutup}

Ragam sastra Bali yang ditemukan di enklave Bali di Pulau Lombok adalah pepaosan, sesonggan, sloka, cicempedan, dan satua. Hilangnya ragam-ragam sastra Bali yang dikenal di wilayah asalnya di enklave Bali di Pulau Lombok dapat disebabkan oleh beberapa faktor, antara lain adalah sebagai berikut.Pertama, tidak ada regenerasi. Bisa jadi, pada awal perkembangannya sastra Bali di enklave Lombok memiliki ragam-ragam seperti yang ditemukan di wilayah asalnya. Akan tetapi seiring berjalannya waktu dan perkembangan zaman, ragam-ragam tertentu punah karena tidak adanya pewarisan kepada generasi berikutnya. Ketiadaan kegiatan pewarisan ini bisa disebabkan oleh beberapa faktor, seperti kekurangtertarikan generasi penerus untuk mempelajari ragam sastra yang bersangkutan karena dianggap tidak banyak manfaatnya, ataupun mula- mula masih terjadi proses pewarisan, tetapi semakin lama semakin luntur, dan pada akhirnya punahlah ragam sastra tersebut.

Kedua, kedatangan komunitas Bali di Lombok lebih banyak disebabkan oleh faktor politik dan perluasan kekuasaan. Sejalan dengan tujuan kedatangan komunitas Bali di Lombok tersebut, dapat diperkirakan bahwa mereka yang menetap di Pulau Lombok adalah golongan para prajurit dan keturunannya, yang biasanya bukanlah pelaku maupun peminat sastra. Berdasarkan latar belakang tersebut, besar kemungkinan bahwa ragam sastra Bali yang tersebar di Lombok hanyalah sebagian kecil yang kebetulan dikuasai oleh golongan prajurit ini.

Ketiga, wilayah Cakranegara merupakan enklave Bali di Pulau Lombok yang memiliki ragam sastra yang paling kaya. Hal ini dapat ditelusuri dari awal kedatangan komunitas Bali di Lombok. Pada awalnya, pemukiman orang Bali di Lombok terkonsentrasi di wilayah-wilayah Cakranegara, Pagutan, Mataram, Pagesangan, dan Pemenang, yang merupakan bekas kerajaan Singasari. Jika dilihat dari sejarah tersebut, Cakranegara merupakan salah-satu pusat kerajaan Bali di Pulau Lombok, sehingga tidaklah mengherankan jika di enklave ini ditemukan ragam sastra yang lebih variatif, karena pusat-pusat kerajaan merupakan wilayah yang subur bagi perkembangan kesastraan. Faktor lain yang mendukung berkembangnya ragam sastra yang lebih variatif di wilayah ini adalah tingkat kemapanan ekonomi yang cukup tinggi. Cakranegara merupakan salah satu jantung perekonomian di Pulau Lombok, sehingga tingkat kemapanan secara ekonomi komunitas Bali di wilayah ini juga lebih tinggi dibandingkan wilayah-wilayah lainnya. Kemampanan secara ekonomi ini merupakan salah satu faktor pendorong 
Karya Sastra yang Tumbuh dan Berkembang ...(Nining Nur Alaini)| 99

suburnya perkembangan sastra di Cakranegara.

\section{Daftar Pustaka}

Damhujin. (2005). "Distribusi Bahasa Bali dan Bahasa Sumbawa di Pulau Lombok: Suatu Kajian Dialektologi”. (Laporan Penelitian). Mataram: Kantor Bahasa Provinsi NTB.

Departemen Pendidikan dan Kebudayaan. (1991). Kamus Besar Bahasa Indonesia. Jakarta.

Djoko Damono, Sapardi. (2005). Pegangan Penelitian Sastra Bandingan. Jakarta:
Pusat Bahasa, Departemen Pendidikan Nasional.

Nada, Thaha. (1999). Sastra Bandingan. (Drs. Aliuddin Mahyudin, M. A., penerjemah). Depok: Fakultas Sastra Universitas Indonesia.

Remak, Henry H. H. (1990). Sastera Bandingan, Kaedah Dan Perspektif. (Zalila Syarif, dkk., penerjemah). Kuala Lumpur: Dewan Bahasa dan Pustaka.

Tuloli, Nani. (1991). Tanggomo Salah Satu Ragam Sastra Lisan Gorontalo. Jakarta: Intermasa. 